\title{
IMPLEMENTASI MULTI ATTRIBUTE FAILURE MODE ANALYSIS PADA PROSES PRODUKSI GALON AIR MINUM DI PT. XYZ
}

\author{
Mario Sariski Dwi Ellianto $^{1}$, Yusuf Eko Nurcahyo ${ }^{2}$ \\ Teknik Manufaktur \\ Politeknik 17 Agustus 1945 Surabaya, Indonesia \\ e-mail : ${ }^{1}$ mariosde6@gmail.com, ${ }^{2}$ yusuf.eko.nurcahyo@gmail.com \\ Diterima: 30 April 2019. Disetujui : 15 Juni 2019. Dipublikasikan : 30 Juni 2019 \\ (C)2019 -TESJ Fakultas Teknik Universitas Maarif Hasyim Latif. Ini adalah artikel dengan \\ akses terbuka di bawah lisensi CC BY 4.0 (https://creativecommons.org/licenses/by/4.0/)
}

\begin{abstract}
ABSTRAK
PT. XYZ adalah industri manufaktur yang bergerak di bidang produksi kemasan dari bahan bijih plastik. Permasalahan yang saat ini dihadapi dalam proses produksi adalah tingginya tingkat waste produk pada khususnya waste defect. Oleh karena itu dibutuhkan identifikasi prioritas resiko dan tindakan perbaikan segera yang harus dilakukan oleh perusahaan. Penggunaan metode Multi Attribute Failure Mode Analysis (MAFMA) diharapkan mampu untuk mengatasi permasalahan waste defect produk dengan cara mendapatkan prioritas resiko tertinggi yang akan dijadikan acuan untuk rekomendasi tindakan perbaikan. Dengan penggunaan metode MAFMA maka diketahui bahwa bobot tertinggi pada defect galon air minum berasal dari penyebab cacat desain ujung Alat Peniup udara (Blow Pin) dengan desain kurang sempurna, diperoleh bobot nilai sebesar 0,234. Dari hasil penyebab cacat tertinggi kemudian diberikan rekomendasi tindakan perbaikan sehingga penyebab cacat produk dapat diperbaiki dengan segera.
\end{abstract}

Kata Kunci: Cacat Produk, Kualitas, MAFMA

\section{PENDAHULUAN}

Dalam era industri manufaktur global saat ini, kebutuhan produk yang berkualitas merupakan syarat mutlak sebuah industri dapat maju berkembang dan sangat berpengaruh terhadap kesuksesan sebuah perusahaan. Perusahaan dituntut untuk meningkatkan kualitas produk yang dihasilkan dan mengontrol waste yang terjadi seperti waste defect agar konsisten mengahsilkan produk sesuai spesifikasi dan kebutuhan pelanggan.

PT. XYZ yang berlokasi di Pasuruan adalah sebuah perusahaan yang bergerak dalam bidang kemasan plastik, produk yang dihasilkan antara lain galon dan cap tutup botol. Perusahaan saat ini mengalami beberapa kendala terutama yang sedang dihadapi oleh departemen produksi yaitu tingginya tingkat waste di berbagai lini khususnya yang menjadi sorotan adalah waste defect/cacat produksi pada pembuatan galon air minum. Berdasarkan data produksi pada bulan februari tahun 2018 tercatat bahwa tingkat cacat produksi sebesar 10,9\%. Berdasarkan data tersebut perlu dilakukan penelitian sehingga penyebab waste defect/cacat produk bisa diidentifikasi dan dilakukan tindakan untuk mengejar target perusahaan yaitu zero waste defect.

Pada penelitian ini akan difokuskan pada departemen produksi galon air minum dikarenakan memiliki tingkat cacat produksi tertinggi. Metode peningkatan kualitas yang digunakan adalah Multi-Attribute Failure Mode Analysis (MAFMA)

\section{METODE PENELITIAN}

Metode MAFMA merupakan pengembangan metode Failure Mode and Effect Analysis (FMEA) dengan menambahkan faktor ekonomi atau biaya ke dalam penilaian resiko. Pada MAFMA penyebab cacat potensial tersebut didasarkan pada nilai bobot tertinggi. Metode MAFMA mengintegrasikan empat faktor pada FMEA yakni chance of failure (occurance), change of non detection, severity dan expected cost. Pada metode MAFMA akan mendapatkan nilai bobot alternatif tertinggi dan meminimalisir nilai bobot yang sama sehingga akan menjadi lebih mudah untuk melakukan tindakan perbaikan berdasarkan hasil metode MAFMA.

\section{HASIL DAN PEMBAHASAN}

\section{Data cacat perusahaan}

Data cacat proses produksi galon air minum berdasarkan data perusahaan dapat dilihat pada Tabel 1. 
Tabel 1. Data Cacat Proses Produksi Galon Air Minum

\begin{tabular}{|l|l|}
\hline No & \multicolumn{1}{c|}{ Cause } \\
\hline 1 & $\begin{array}{l}\text { Desain ujung Alat Peniup udara (Blow Pin) kurang } \\
\text { sempurna (Cause A) }\end{array}$ \\
\hline 2 & Pemasangan Alat Peniup udara tidak sentris (Cause B) \\
\hline 3 & Temperatur Diehead kurang (Cause C) \\
\hline 4 & Inspeksi kurang ketat (Cause D) \\
\hline 5 & Operator selector tidak teliti (Cause E) \\
\hline
\end{tabular}

Penggunaan metode MAFMA ini dimulai dengan merancang kuesioner yang terbagi menjadi 4 kriteria yaitu change of failure (occurrence), detection, severity, dan expected cost. Dari data kuisioner yang didapat, kemudian dilakukan perhitungan yaitu berupa matrik perbandingan tiap alternatif dari setiap aspek kriteria yang dapat dilihat pada Tabel 2 sampai Tabel 5.

Tabel 2. Matrik Perbandingan Preferensi Berpasangan Aspek Severity

\begin{tabular}{|l|c|c|c|c|c|}
\hline \multicolumn{6}{|c|}{ MATRIK PERBANDINGAN PREFERENSI BERPASANGAN } \\
\hline & CAUSE A & CAUSE B & CAUSE C & CAUSE D & CAUSE E \\
\hline CAUSE A & 1 & 1 & 1 & 1 & 2 \\
\hline CAUSE B & 1 & 1 & 1 & 1 & 3 \\
\hline CAUSE C & 1 & 1 & 1 & 1 & 2 \\
\hline CAUSE D & 1 & 1 & 1 & 1 & 2 \\
\hline CAUSE E & $1 / 2$ & $1 / 3$ & $1 / 2$ & $1 / 2$ & 1 \\
\hline
\end{tabular}

Tabel 3. Matrik Perbandingan Preferensi Berpasangan Aspek Occurence

\begin{tabular}{|c|c|c|c|c|c|}
\multicolumn{6}{|c|}{ MATRIK PERBANDINGAN PREFERENSI BERPASANGAN } \\
\hline & CAUSE A & CAUSE B & CAUSE C & CAUSE D & CAUSE E \\
\hline CAUSE A & 1 & 1 & 1 & 2 & 2 \\
\hline CAUSE B & 1 & 1 & 1 & 1 & 2 \\
\hline CAUSE C & 1 & 1 & 1 & 1 & 1 \\
\hline CAUSE D & $1 / 2$ & 1 & 1 & 1 & 1 \\
\hline CAUSE E & $1 / 2$ & $1 / 2$ & 1 & 1 & 1 \\
\hline
\end{tabular}

Tabel 4. Matrik Perbandingan Preferensi Berpasangan Aspek Detection

\begin{tabular}{|c|c|c|c|c|c|}
\hline \multicolumn{6}{|c|}{ MATRIK PERBANDINGAN PREFERENSI BERPASANGAN } \\
\hline & CAUSE A & CAUSE B & CAUSE C & CAUSE D & CAUSE E \\
\hline CAUSE A & 1 & 1 & 1 & 1 & 1 \\
\hline CAUSE B & 1 & 1 & 1 & 1 & 1 \\
\hline CAUSE C & 1 & 1 & 1 & 2 & 2 \\
\hline CAUSE D & 1 & 1 & $1 / 2$ & 1 & 2 \\
\hline CAUSE E & 1 & 1 & $1 / 2$ & $1 / 2$ & 1 \\
\hline
\end{tabular}

Tabel 5. Matrik Perbandingan Preferensi Berpasangan Aspek Expected Cost

\begin{tabular}{|l|c|c|c|c|c|}
\multicolumn{6}{|c|}{ MATRIK PERBANDINGAN PREFERENSI BERPASANGAN } \\
\hline & CAUSE A & CAUSE B & CAUSE C & CAUSE D & CAUSE E \\
\hline CAUSE A & 1 & 1 & 1 & 2 & 3 \\
\hline CAUSE B & 1 & 1 & 1 & 1 & 1 \\
\hline CAUSE C & 1 & 1 & 1 & 2 & 2 \\
\hline CAUSE D & $1 / 2$ & 1 & $1 / 2$ & 1 & 2 \\
\hline CAUSE E & $1 / 3$ & 1 & $1 / 2$ & $1 / 2$ & 1 \\
\hline
\end{tabular}

Setelah itu dapat dilakukan perhitungan metode MAFMA, dengan memasukkan angkaangka yang terdapat pada tabel matrik perbandingan berpasangan dan menyusunnya dengan menggunakan pendekatan Analytic Hierarchy Process, kemudian menjumlahkan masing-masing kolom yang ada seperti yang terlihat pada Tabel 6 sampai Tabel 9.

Tabel 6. Perhitungan Matrik Perbandingan Preferensi Berpasangan Aspek Severity

\begin{tabular}{|c|c|c|c|c|c|}
\multicolumn{6}{|c|}{ MATRIK PERBANDINGAN PREFERENSI BERPASANGAN } \\
\hline & CAUSE A & CAUSE B & CAUSE C & CAUSE D & CAUSE E \\
\hline CAUSE A & 1 & 1 & 1 & 1 & 2 \\
\hline CAUSE B & 1 & 1 & 1 & 1 & 3 \\
\hline CAUSE C & 1 & 1 & 1 & 1 & 2 \\
\hline CAUSE D & 1 & 1 & 1 & 1 & 2 \\
\hline CAUSE E & $1 / 2$ & $1 / 3$ & $1 / 2$ & $1 / 2$ & 1 \\
\hline TOTAL & $41 / 2$ & $41 / 3$ & $41 / 2$ & $41 / 2$ & 10 \\
\hline
\end{tabular}

Tabel 7. Perhitungan Matrik Perbandingan Preferensi Berpasangan Aspek Occurence

\begin{tabular}{|c|c|c|c|c|c|}
\hline \multicolumn{6}{|c|}{ MATRIK PERBANDINGAN PREFERENSI BERPASANGAN } \\
\hline & CAUSE A & CAUSE B & CAUSE C & CAUSE D & CAUSE E \\
\hline CAUSE A & 1 & 1 & 1 & 2 & 2 \\
\hline CAUSE B & 1 & 1 & 1 & 1 & 2 \\
\hline CAUSE C & 1 & 1 & 1 & 1 & 1 \\
\hline CAUSE D & $1 / 2$ & 1 & 1 & 1 & 1 \\
\hline CAUSE E & $1 / 2$ & $1 / 2$ & 1 & 1 & 1 \\
\hline TOTAL & 4 & $41 / 2$ & 5 & 6 & 7 \\
\hline
\end{tabular}

Tabel 8. Perhitungan Matrik Perbandingan Preferensi Berpasangan Aspek Detection

\begin{tabular}{|c|c|c|c|c|c|}
\hline \multicolumn{6}{|c|}{ MATRIK PERBANDINGAN PREFERENSI BERPASANGAN } \\
\hline & CAUSE A & CAUSE B & CAUSE C & CAUSE D & CAUSE E \\
\hline CAUSE A & 1 & 1 & 1 & 1 & 1 \\
\hline CAUSE B & 1 & 1 & 1 & 1 & 1 \\
\hline CAUSE C & 1 & 1 & 1 & 2 & 2 \\
\hline CAUSE D & 1 & 1 & $1 / 2$ & 1 & 2 \\
\hline CAUSE E & 1 & 1 & $1 / 2$ & $1 / 2$ & 1 \\
\hline TOTAL & 5 & 5 & 4 & $51 / 2$ & 7 \\
\hline
\end{tabular}


Tabel 9. Perhitungan Matrik Perbandingan Preferensi Berpasangan Aspek Expected Cost

\begin{tabular}{|c|c|c|c|c|c|}
\hline \multicolumn{6}{|c|}{ MATRIK PERBANDINGAN PREFERENSI BERPASANGAN } \\
\hline & CAUSE A & CAUSE B & CAUSE C & CAUSE D & CAUSE E \\
\hline CAUSE A & 1 & 1 & 1 & 2 & 3 \\
\hline CAUSE B & 1 & 1 & 1 & 1 & 1 \\
\hline CAUSE C & 1 & 1 & 1 & 2 & 2 \\
\hline CAUSE D & $1 / 2$ & 1 & $1 / 2$ & 1 & 2 \\
\hline CAUSE E & $1 / 3$ & 1 & $1 / 2$ & $1 / 2$ & 1 \\
\hline TOTAL & $35 / 6$ & 5 & 4 & $61 / 2$ & 9 \\
\hline
\end{tabular}

Setelah itu dapat dilakukan perhitungan vektor preferensi dengan menjumlahkan tiap barisnya seperti yang terlihat pada Tabel 10 sampai dengan Tabel 13.

Tabel 10. Perhitungan Vektor Preferensi Aspek Severity

\begin{tabular}{|c|c|c|c|c|c|c|}
\hline \multicolumn{6}{|c|}{ VEKTOR PREFERENSI ASPEK SEVERITY } & \multirow{2}{*}{$\begin{array}{c}\text { Vektor } \\
\text { Preferensi }\end{array}$} \\
\hline & CAUSE A & CAUSE B & CAUSE C & CAUSE D & CAUSE E & \\
\hline CAUSE A & $2 / 9$ & $1 / 4$ & $2 / 9$ & $2 / 9$ & $1 / 5$ & 0,219 \\
\hline CAUSE B & $2 / 9$ & $1 / 4$ & $2 / 9$ & $2 / 9$ & $2 / 7$ & 0,239 \\
\hline CAUSE C & $2 / 9$ & $1 / 4$ & $2 / 9$ & $2 / 9$ & $1 / 5$ & 0,219 \\
\hline CAUSE D & $2 / 9$ & $1 / 4$ & $2 / 9$ & $2 / 9$ & $1 / 5$ & 0,219 \\
\hline CAUSE E & $1 / 9$ & 0 & $1 / 9$ & $1 / 9$ & 0 & 0,102 \\
\hline \multicolumn{6}{|c|}{ TOT } & 1 \\
\hline
\end{tabular}

Tabel 11. Perhitungan Vektor Preferensi Aspek Occurence

\begin{tabular}{|c|c|c|c|c|c|c|}
\hline \multicolumn{6}{|c|}{ VEKTOR PREFERENSI ASPEK OCCURENCE } & \multirow{2}{*}{$\begin{array}{c}\text { Vektor } \\
\text { Preferens }\end{array}$} \\
\hline & CAUSE A & CAUSE B & CAUSE C & CAUSE D & CAUSE E & \\
\hline CAUSE A & $1 / 4$ & $2 / 9$ & $1 / 5$ & $1 / 3$ & $2 / 7$ & 0,258 \\
\hline CAUSE B & $1 / 4$ & $2 / 9$ & $1 / 5$ & $1 / 6$ & $2 / 7$ & 0,225 \\
\hline CAUSE C & $1 / 4$ & $2 / 9$ & $1 / 5$ & $1 / 6$ & $1 / 7$ & 0,196 \\
\hline CAUSE D & $1 / 8$ & $2 / 9$ & $1 / 5$ & $1 / 6$ & $1 / 7$ & 0,171 \\
\hline CAUSE E & $1 / 8$ & $1 / 9$ & $1 / 5$ & $1 / 6$ & $1 / 7$ & 0,149 \\
\hline \multicolumn{6}{|c|}{ TOTAL } & 1 \\
\hline
\end{tabular}

Tabel 12. Perhitungan Vektor Preferensi Aspek Detection

\begin{tabular}{|c|c|c|c|c|c|c|}
\hline \multicolumn{6}{|c|}{ VEKTOR PREFERENSI ASPEK DETECTION } & \multirow{2}{*}{$\begin{array}{c}\text { Vektor } \\
\text { Preferens }\end{array}$} \\
\hline & CAUSE A & CAUSE B & CAUSE C & CAUSE D & CAUSE E & \\
\hline CAUSE A & $1 / 5$ & $1 / 5$ & $1 / 4$ & $1 / 5$ & $1 / 7$ & 0,195 \\
\hline CAUSE B & $1 / 5$ & $1 / 5$ & $1 / 4$ & $1 / 5$ & $1 / 7$ & 0,195 \\
\hline CAUSE C & $1 / 5$ & $1 / 5$ & $1 / 4$ & $1 / 3$ & $2 / 7$ & 0,260 \\
\hline CAUSE D & $1 / 5$ & $1 / 5$ & $1 / 8$ & $1 / 5$ & $2 / 7$ & 0,199 \\
\hline CAUSE E & $1 / 5$ & $1 / 5$ & $1 / 8$ & 0 & $1 / 7$ & 0,152 \\
\hline \multicolumn{6}{|c|}{ TOTAL } & 1 \\
\hline
\end{tabular}

Tabel 13. Perhitungan Vektor Preferensi Aspek Expected Cost

\begin{tabular}{|c|c|c|c|c|c|c|}
\hline \multicolumn{6}{|c|}{ VEKTOR PREFERENSI ASPEK EXPECTED COST } & \multirow{2}{*}{$\begin{array}{l}\text { Vektor } \\
\text { Preferensi }\end{array}$} \\
\hline & CAUSE A & CAUSE B & CAUSE C & CAUSE D & CAUSE E & \\
\hline CAUSE A & $1 / 4$ & $1 / 5$ & $1 / 4$ & $1 / 3$ & $1 / 3$ & 0,270 \\
\hline CAUSE B & $1 / 4$ & $1 / 5$ & $1 / 4$ & $1 / 6$ & $1 / 9$ & 0,195 \\
\hline CAUSE C & $1 / 4$ & $1 / 5$ & $1 / 4$ & $1 / 3$ & $2 / 9$ & 0,248 \\
\hline CAUSE D & $1 / 8$ & $1 / 5$ & $1 / 8$ & $1 / 6$ & $2 / 9$ & 0,166 \\
\hline CAUSE E & 0 & $1 / 5$ & $1 / 8$ & 0 & $1 / 9$ & 0,120 \\
\hline \multicolumn{6}{|c|}{ TOTAL } & 1 \\
\hline
\end{tabular}

Setelah itu didapat hasil vektor preferensi dari masing-masing aspek kriteria seperti pada Tabel 14.

Tabel 14. Vektor Preferensi dari masing-masing aspek kriteria

\begin{tabular}{|c|c|c|c|c|}
\hline \multicolumn{5}{|c|}{ KRITERIA ASPEK } \\
\hline & SEVERITY & OCCURENCE & DETECTION & EXPECTED COST \\
\hline CAUSE A & 0,219 & 0,258 & 0,195 & 0,270 \\
\hline CAUSE B & 0,239 & 0,225 & 0,195 & 0,195 \\
\hline CAUSE C & 0,219 & 0,196 & 0,260 & 0,248 \\
\hline CAUSE D & 0,219 & 0,171 & 0,199 & 0,166 \\
\hline CAUSE E & 0,102 & 0,149 & 0,152 & 0,120 \\
\hline
\end{tabular}

Setelah didapat hasil vektor preferensi dari masing-masing aspek kriteria, langkah selanjutnya adalah menghitung matrik perbandingan preferensi berpasangan antar kriteria seperti pada Tabel 15.

Tabel 15. Matrik Perbandingan Preferensi Berpasangan Antar Kriteria

\begin{tabular}{|c|c|c|c|c|}
\hline \multicolumn{5}{|c|}{ MATRIK PERBANDINGAN PREFERENSI BERPASANGAN } \\
& ANTAR KRITERIA & \\
\hline & SEVERITY & OCCURRENCE & DETECTION & $\begin{array}{c}\text { EXPECTED } \\
\text { COST }\end{array}$ \\
\hline SEVERITY & 1 & 1 & 2 & 2 \\
\hline OCCURRENCE & 1 & 1 & 2 & 2 \\
\hline DETECTION & $1 / 2$ & $1 / 2$ & 1 & 2 \\
\hline $\begin{array}{c}\text { EXPECTED } \\
\text { COST }\end{array}$ & $1 / 2$ & $1 / 2$ & $1 / 2$ & 1 \\
\hline
\end{tabular}

Tabel 16. Matrik Perbandingan Preferensi Berpasangan Antar Kriteria

\begin{tabular}{|c|c|c|c|c|}
\hline \multicolumn{5}{|c|}{ MATRIK PERBANDINGAN PREFERENSI BERPASANGAN } \\
ANTAR KRITERIA
\end{tabular}

Setelah itu dapat dilakukan perhitungan dengan memasukkan angka-angka yang terdapat pada tabel sebelumnya dan menyusunnya lagi dengan menggunakan pendekatan metode AHP, 
Tabel 17. Perhitungan Vektor Preferensi Antar Kriteria

\begin{tabular}{|c|c|c|c|c|c|}
\hline & & & & & \\
KRITERIA & SEVERITY & OCCURRENCE & DETECTION & EXPECTED COST & $\begin{array}{c}\text { Vektor Preferensi } \\
\text { Antar Kriteria }\end{array}$ \\
\hline SEVERITY & 0,333 & 0,333 & 0,364 & 0,286 & 0,329 \\
\hline OCCURRENCE & 0,333 & 0,333 & 0,364 & 0,286 & 0,329 \\
\hline DETECTION & 0,167 & 0,167 & 0,182 & 0,286 & 0,200 \\
\hline EXPECTED COST & 0,167 & 0,167 & 0,091 & 0,143 & 0,142 \\
\hline
\end{tabular}

kemudian menjumlahkan masing-masing kolom yang ada seperti yang terlihat pada Tabel 16.

Setelah itu dapat dilakukan perhitungan vektor preferensi antar kriteria dengan mencari rata-rata tiap barisnya, seperti yang terlihat pada Tabel 17.

\section{Nilai MAFMA}

Metode MAFMA mengintegrasikan empat faktor yakni occurence, detection, severity dan expected cost. Biaya akibat cacat proses produksi dihitung dengan perbandingan kualitatif. Formulasi rangking prioritas penyebab cacat proses produksi dilakukan dengan pendekatan AHP, sehingga mempermudah analisis secara efektif dan efisien.

Setelah didapatkan masing-masing vektor preferensi antar alternatif dan vektor preferensi kriteria aspek, langkah selanjutnya mengkalikan vektor preferensi antar alternatif dengan vektor preferensi kriteria aspek untuk menghitung skor masing-masing alternatif pada MAFMA. Berikut hasil perhitungan skor masing-masing alternatif ditunjukkan pada Tabel 18.

Tabel 18. Perhitungan Skor Masing-Masing Alternatif

\begin{tabular}{|l|l|}
\hline CAUSE A & 0,234 \\
\hline CAUSE B & 0,219 \\
\hline CAUSE C & 0,224 \\
\hline CAUSE D & 0,192 \\
\hline CAUSE E & 0,130 \\
\hline
\end{tabular}

Tabel 19. Perhitungan Nilai CR

\begin{tabular}{|l|l|}
\hline \multicolumn{2}{|l|}{ Perhitungan Nilai CR } \\
\hline$a$ & 4,061 \\
\hline$n$ & 4 \\
\hline$R I$ (tabel) & 0,89 \\
\hline$C I=\frac{a-n}{n-1}$ & 0,020 \\
\hline$C R=\frac{C I}{R I}$ & 0,022 \\
\hline
\end{tabular}

Langkah selanjutnya adalah menghitung nilai CR (Consistency Ratio) untuk mengetahui kekonsistenan dari tiap data. Nilai CR tidak boleh lebih dari 0,1, jika nilai CR lebih dari 0,1 maka data dianggap tidak konsisten. Berikut ini adalah perhitungan nilai CR seperti yang terlihat pada Tabel 19.

Berdasarkan hasil perhitungan pada Tabel 19 , terlihat bahwa nilai $\mathrm{CR}=0,022$ sehingga data yang diperoleh bisa dikatakan konsisten.

\section{Analisa Multi Attribute Failure Mode Analysis (MAFMA)}

Pada Tabel 20 perhitungan skor masingmasing alernatif terlihat skor tertinggi MAFMA yaitu pada penyebab cacat desain ujung Alat Peniup udara (Blow Pin) kurang sempurna (Cause A) dengan nilai 0,234. Cause A tertinggi dipilih karena menunjukkan penyebab cacat yang tertinggi. Dengan pendekatan metode MAFMA maka dapat dihilangkan nilai prioritas resiko yang sama, maka dengan penggunaan metode MAFMA akan diperoleh nilai penyebab cacat yang berbeda antar penyebab cacat sehingga hanya diperoleh satu nilai yang tertinggi sebagai acuan untuk dilakukan rekomendasi tindakan perbaikan.

\section{Rekomendasi Perbaikan}

Langkah selanjutnya untuk menurunkan jumlah cacat yaitu memberi usulan perbaikan kepada perusahaan. Pada pendekatan metode MAFMA, penyebab cacat yang paling kritis bisa diketahui dengan melihat bobot tertinggi. Dari hasil rekap nilai MAFMA maka dapat diambil beberapa alternatif perbaikan.

Berdasarkan rangking pembobotan maka akan dijelaskan beberapa usulan tindakan perbaikan terhadap proses produksi sesuai dengan kondisi dari perusahaan sendiri.

a. Usulan perbaikan penyebab cacat desain ujung Alat Peniup Udara (Blow Pin) kurang sempurna

Usulan untuk perbaikan penyebab cacat pada desain ujung Alat Peniup Udara (Blow Pin) sehingga menyebabkan tidak lancarnya proses peniupan udara ke cavity dengan langkah pertama yaitu departemen dies mendesain ulang bentuk Alat Peniup Udara yang tidak menghambat proses peniupan udara. Langkah kedua adalah perbaikan ujung Alat Peniup Udara yang sudah ada tetapi dapat menyebabkan mesin menganggur dalam waktu lama. 
Tabel 20. Rangking Pembobotan untuk Alternatif Perbaikan

\begin{tabular}{|l|l|c|c|}
\hline \multicolumn{1}{|c|}{ Penyebab } & \multicolumn{1}{|c|}{ Kendali } & $\begin{array}{c}\text { Bobot Alternatif } \\
\text { dari MAFMA }\end{array}$ & $\begin{array}{c}\text { Rangking } \\
\text { Pembobotan }\end{array}$ \\
\hline $\begin{array}{l}\text { Desain ujung Alat Peniup udara (Blow } \\
\text { Pin) kurang sempurna }\end{array}$ & Penggantian ujung Alat Peniup Udara & 0,234 & 1 \\
\hline $\begin{array}{l}\text { Pemasangan Alat Peniup udara tidak } \\
\text { sentris }\end{array}$ & Perbaikan Alat Peniup Udara & 0,219 & 3 \\
\hline Temperatur Diehead kurang & Maintenance temperatur diehead & 0,224 & 2 \\
\hline Inspeksi kurang ketat & Briefing Operator dan Quality Control & 0,192 & 4 \\
\hline Operator selector tidak teliti & Briefing Operator selector & 0,13 & 5 \\
\hline
\end{tabular}

b. Usulan perbaikan penyebab cacat pemasangan Alat Peniup Udara tidak sentris Usulan untuk perbaikan cacat pemasangan Alat Peniup Udara yang tidak sentris atau dalam posisi miring adalah dengan rutin melakukan tindakan perawatan preventive mesin sebelum dilakukan proses produksi sehingga posisi komponen pada mesin dapat terjaga dengan baik.

c. Usulan perbaikan penyebab cacat temperatur diehead kurang

Usulan untuk memperbaiki penyebab cacat temperatur diehead yang selalu berada pada posisi kurang pada derajad temperaturnya adalah dengan dilakukan preventive maintenance secara berkala dan setting mesin harus sesuai dengan SOP agar temperatur tidak selalu mengalami perubahan. setting temperatur pada diehead harus konstan. Operator juga berperan dalam perawatan mesin sehingga setting temperatur pada semua daerah yang dilewati material plastik dapat berfungsi dengan normal.

d. Usulan perbaikan penyebab cacat Inspeksi kurang ketat

Usulan untuk memperbaiki penyebab cacat Inspeksi atau pengamatan pada produk jadi yang kurang ketat sehingga menyebabkan banyak produk cacat yang lolos ke konsumen adalah dengan rutin untuk melakukan briefing pada operator mesin, operator selector dan juga operator quality control.

e. Usulan perbaikan penyebab cacat operator selector tidak teliti

Usulan untuk memperbaiki penyebab cacat operator selector yang tidak teliti menyeleksi produk jadi sehingga banyak produk yang cacat lolos ke konsumen adalah dengan rutin melakukan briefing pada operator selector dan melakukan pelatihan pada operator selector sehingga kompetensi operator tetap terjaga.

\section{PENUTUP}

Berdasarkan hasil perhitungan MAFMA diperoleh nilai skor tertinggi yaitu pada cause A (desain ujung Alat Peniup udara atau Blow Pin kurang sempurna) dengan nilai 0,234 . Cause A tertinggi dipilih karena menunjukkan penyebab cacat yang tertinggi dan harus segera dilakukan tindakan perbaikan. Dengan pendekatan metode MAFMA maka dapat diperoleh nilai penyebab cacat yang spesifik sebagai acuan untuk diberikan rekomendasi tindakan perbaikan.

Usulan perbaikan untuk prioritas tertinggi yang direkomendasikan pada perusahaan adalah dengan langkah pertama yaitu departemen dies mendesain ulang bentuk Alat Peniup Udara yang tidak menghambat proses peniupan udara. Langkah kedua adalah perbaikan ujung Alat Peniup Udara yang sudah ada.

\section{DAFTAR PUSTAKA}

Braglia, M. (2000). MAFMA: multi-attribute failure mode analysis. International Journal of Quality \& Reliability Management, 17(9), 1017-1033.

Evans, J. R., Lindsay, W. M., \& Fitriati, A. R. (2007). Pengantar Six Sigma. Salemba Empat.

Gaspersz, V. (2012). All in one management toolbook. Bogor: Tri-Al Bros Publishing.

Hafiish, F. W. Al, \& Supriyanto, H. (2010). Peningkatan Kualitas dengan Pendekatan Konsep Lean dan Multi Attribute Failure Mode Analysis (Studi Kasus: PT. Nestle Indonesia, Pasuruan). Retrieved from http://digilib.its.ac.id/public/ITSUndergraduate-10673-Paper.pdf

Kristyanto, R., Sugiono, S., \& Yuniarti, R. (2015). Analisis Risiko Operasional Pada Proses Produksi Gula Dengan Menggunakan Metode Multi-attribute Failure Mode Analysis (Mafma)(Studi Kasus: Pg. Kebon Agung Malang). Jurnal Rekayasa Dan Manajemen Sistem Industri, 3(3), p592-601.

Press, D. (2003). Guidelines for Failure Mode and Effects Analysis (FMEA), for Automotive, Aerospace, and General Manufacturing Industries. CRC Press. 
MSD Ellianto, dkk./ Teknika : Engineering and Sains Journal, Vol. 3, No.1, Juni 2019, 31-36

Halaman ini sengaja dikosongkan 